\title{
Editorial
}

\section{Emerging health care reform issues in the US presidential debate}

\author{
KENNETH E. THORPE* \\ Rollins School of Public Health, Emory University, Atlanta, USA
}

The 2008 presidential election in the United States has again elevated the issue of health care reform to center stage. Reform proposals are proliferating in the states as well as nationally. Virtually all candidates - both Republican and Democratic - running for President have outlined their plans for reforming health care. The renewed interest in health care reform reflects the fact that several key measures of the performance of the US health care system continue to deteriorate. Since 2000, the (nominal) cost of private health insurance has doubled. ${ }^{1}$ Over the same period, the number of Americans without health insurance has increased from 38.7 million to 47 million in $2006 .{ }^{2}$ Objective measures of the quality of health care provided to chronically ill patients are also of concern; such patients only receive approximately $56 \%$ of the clinically recommended preventive health care (McGlynn et al., 2003).

Of course, these problems plaguing the American health care system are not new. However, what is new is the flurry of activity at the state level. Absent federal leadership of the issue over the past seven years, two states - Vermont and Massachusetts - have recently passed comprehensive health care reform plans. Massachusetts passed an individual mandate that requires all residents of the state to have health insurance. Health plans offered through the state's insurance "connector" offer comprehensive benefits. Individuals can purchase a low cost sharing or a higher cost sharing version of these plans (premiums differ by about $\$ 35$ per month for the two plans). ${ }^{3}$ Certain exceptions to the law were made for individuals and families earning more than three times the US poverty level. These individuals may apply for a waiver from the requirement and remain

\footnotetext{
*Correspondence to: Dr. Kenneth E. Thorpe, Robert W. Woodruff Professor and Chair, Department of Health Policy and Management, Rollins School of Public Health, Emory University, 1518 Clifton Road, NE, Atlanta, GA 30322, USA. Email: kthorpe@sph.emory.edu

1 http://www.kff.org/insurance/upload/7670.pdf

$2 \mathrm{http}: / /$ www.census.gov/prod/2001pubs/p60-215.pdf

3 For more detail see, http://www.massresources.org/pages.cfm?contentID $=81$ \&pageID=13 \&Subpages $=$ yes
} 
uninsured if the cost of insurance is deemed unaffordable by the state insurance connector. $^{4}$

Vermont passed a broader set of reforms involving the redesign of how health care is delivered to chronically ill patients, accelerated the diffusion of health information technologies to be used by primary care physicians, and created a new focus and programs on prevention and public health initiatives. In addition, the Vermont legislation requires that the percentage of the population with insurance must rise from $90 \%$ to $96 \%$ of all Vermonters by 2010 (Thorpe, 2007). Several other states, including California, Pennsylvania, and Illinois are contemplating similar reforms. ${ }^{5}$

During the past two presidential cycles in 2000 and 2004, the health reform proposals from the Democratic candidates were incremental expansions of existing health insurance programs. None of the major plans proposed universal coverage. Instead, most of the "competition" among the candidates' plans centered on which incremental plan provided the most coverage at the lowest federal cost. Also left out of the plans were comprehensive efforts designed to reduce the cost of health insurance. Health plans from the Republican candidates in 2000, and President Bush's proposal in 2004 were even more tepid. The Bush plan would have provided refundable tax credits designed to reduce the cost of insurance and thus increase enrollment among the uninsured. However, the dollar value of these tax credits was low and they phased out at $\$ 60,000$ for families. As a result, even the most aggressive Republican plan would, if adopted, extend coverage to only approximately 5-6 million uninsured.

The health care reform proposals advanced by the Democratic presidential candidates this year differ significantly from the previous two cycles. Even Republican presidential candidates are floating health care reform proposals during the primary election cycle. The key difference in this election is that virtually all the plans have proposed reforms that go beyond health financing reforms designed to cover the uninsured. The broadened focus designed to make health care more affordable, improve the quality of care in addition to reducing the number of uninsured represents a new political strategy and direction. The focus on making health care more affordable reflects the sharp increase in health insurance premiums since 2000. Between 2000 and 2007 the cost of private health insurance has doubled. ${ }^{6}$ Perhaps the most important reason for these more comprehensive reforms concerns the strategy of how to

4 The commonwealth has published a matrix defining affordability of health care by family income and the share of family income that health insurance would cost. If the least expensive plan exceeds this definition of affordability, the individual or family may apply for a waiver and be excluded from the individual mandate requirement.

5 See a summary at http://www.nga.org/Files/pdf/0707HEALTHREFORM.PDF

6 Kaiser Family Foundation, Employer Health Benefits, 2007. Kaiser Family Foundation, Menlo Park, California, 2007, accessed at http:/www.kff.org/insurance/7672/upload/EHBS-2007-FullReport-PDF.pdf 
politically proceed with comprehensive health care reforms. Over 250 million Americans have some form of private or public health insurance coverage. Of this total, approximately 200 million receive coverage through their employer. Those with health insurance are concerned primarily with the affordability of coverage; a topic largely ignored over the past two presidential cycles. A second key fact is that adults with health insurance vote. During the 2004 mid-term elections, $96 \%$ of voters had health insurance, thus the recognition that $85 \%$ of Americans were already insured and that their main concern is over the affordability of health care has assumed an important role in shaping the Democratic health care proposals.

These reforms recognize the dominant financial role that patients with multiple chronic health care conditions assume in the US health care system. Overall, such patients account for at least $75 \%$ of total US national health care spending. Moreover, the doubling of obesity in the US to $33 \%$ over the past 20 years by itself accounts for nearly a third of the rise in spending. This rise in spending is associated with both rising incidence and prevalence of chronic diseases like diabetes and more intensive treatment of overweight and obese patients. 7

The US health care system, however, was built to deliver health care services to acutely ill patients requiring episodic care. As a result, chronically ill patients receive only $56 \%$ of the clinically recommended preventive and maintenance care recommended by physicians. In light of these facts, virtually all of the Democratic presidential candidates have developed specific proposals designed to modernize the delivery of health care to more effectively prevent and manage chronic illness. These proposals include payment reform proposals designed to assure that chronically ill patients receive all clinically recommended preventive services. These annual payments to primary care physicians or multi-speciality clinics would cover the expected costs of treating chronically ill patients such as diabetics throughout the year.

A second major difference in the Democratic plans of 2008 is the focus on universal coverage among most, though not all of the candidates. Senators Clinton and Edwards have both called for a requirement that individuals acquire health insurance. They could either receive coverage through their place of employment, or alternatively (in the Clinton case) purchase coverage through the plans offered to federal workers - the Federal Employees Health Benefits Program (FEHBP). Senator Obama's plan would establish a national health insurance exchange - similar to the one passed in Massachusetts - that would allow employers and individuals to purchase coverage with federal financial assistance for low and moderate income families. While Senator Obama would require all children to have coverage, his plan does not require adults to do so. Instead, he proposes federal subsidies that would reduce the cost of insurance with the expectation from his campaign that most of the

7 See statistics at www.fightchronicdisease.org/partnerpack 
uninsured would purchase health insurance. While this approach may have less appeal to core Democrats in the primary, the voluntary approach may prove an effective approach when facing the Republican candidate in the upcoming general election.

The Democratic plans are similar in other regards. The leading three candidates - Clinton, Edwards and Obama - have established the health insurance plans offered to members of Congress and federal workers as the standard of care. All would provide federal financial assistance to the uninsured (based on income) to make the cost of care less expensive. Senator Clinton would also limit what individuals and families have to pay for insurance as a share of family income. To date, however, the campaigns have not released the detail on the extent of these federal subsidies or the caps in the case of the Clinton plan.

The Republican plans are more modest and move in a different direction than the Democratic plans. None of the leading candidates move to universal coverage. Rudolph Giuliani has essentially offered a plan similar to the one developed by President Bush. He would provide \$7,500 and \$15,000 (for families) tax credit to purchase health insurance. This would replace the existing favorable tax treatment of employer-provided health benefits. Senator McCain would also eliminate the current favorable tax treatment of employer sponsored insurance. In its place, he would provide federal tax credits of $\$ 2,500$ per individual and $\$ 5,000$ per family to purchase health insurance. I estimate that the number of newly insured under the most aggressive Republican proposal is well under 10 million. Moreover, the thrust of the proposals is to expand coverage in the individual (nongroup) insurance market. The Republican efforts to control the rise in health care spending focus on more choice of health plans, additional information on prices and quality of health care providers and procedures and high cost sharing to limit moral hazard. Mitt Romney's plan would allow the states to develop their own health care plans using existing streams of federal funding flowing to each state to make coverage more affordable. There are, however, concerns about the dramatic variation in federal funding flowing to the states. Also at issue is whether the level of federal funding available at the state level would be sufficient to extend coverage.

The high and rising cost of health insurance has again placed health care reform center stage in the American political debate. The outcome of the Presidential election in 2008, along with the Congressional elections, will play a key role in deciding how comprehensive a reform is passed (ranging from virtually no change to the broader structural changes in health care delivery and universal coverage). Many of the states are not waiting until the issue is resolved at the federal level and are developing their own approaches. What does seem certain is the push for broader more comprehensive reforms of the American health care system will continue to mount. The 2008 elections will go a long way toward answering the question of how fast such reforms will be adopted. 
Emerging health care reform issues in the US presidential debate 5

\section{References}

McGlynn, E. et al. (2003), 'The quality of health care delivered to adults in the United States', New England Journal of Medicine, 348: 2634-2645.

Thorpe, K. E. (2007), 'Vermont's catamount health: a roadmap for health care reform?', Health Affairs, 26(6): w703-w705. 